\title{
Surgery of the hymen: from myth to modernisation
}

\author{
V. Raveenthiran
}

Received: 9 May 2009 / Accepted: 18 May 2009

(C) Association of Surgeons of India 2009

Curiosity provoked by the hymen among laity and learned, is disproportionate to its dimensions. Embryologically, it is a membranous remnant at the junction of sino-vaginal bulb and mullerian ducts. Although originally it was considered as a vestigial structure, its evolutionary role in protecting female infants from pelvic infections has recently been postulated [1]. Until now, surgery of hymen is largely limited to 'hymenotomy' when it is congenitally imperforated. In this issue of Indian Journal of Surgery (2009; 71:221-223) Vishwa Prakash has described his technique of hymenoplasty (more correctly hymenorrhaphy). This unusual paper provokes several scientific, ethical and social concerns.

First of all, why would somebody seek reconstruction of torn hymen? Intact hymen is long held as a sign of virginity. Blood stained bed-sheets are expected on nuptial nights and they are vividly portrayed in popular cinema to represent bleeding from ruptured hymen on defloration. Deviation from this hegemonic, religious expectation has harmful repercussion on the woman which ranges from shame to 'honour killing' [2]. This misconception must have originated probably because of phonetic resemblance between the two Greek words "Hymen" and "Hymn". The word "hymen" means "membrane" as evident from terms such as "hymenology" (anatomical study of membranes), "hymenopterons" (insects with membranous wings) and "hymenolepis" (tapeworms with membrane suckers). According to some etymologists, even the word "human" originated from the root word "hymen" because human fetus is cov-

V. Raveenthiran $(\bowtie)$

Associate Editor, Indian Journal of Surgery,

A11, Rani Seethai Achi (RSA) Housing Complex,

Annamalai Nagar - 608 002,

Tamil Nadu, India

E-mail: vrthiran@yahoo.co.in ered with amniotic membrane during gestation. Appropriately, membranous remnant of vagina is termed as "hymen vaginalis". On the other hand, the word "hymn" (frequently misspelt as "hymen" in English translations) refers to a minor God in Greek mythology (Figure). He is believed to preside over marriage ceremonies by holding a torch in his hands [3]. Invocation songs sung during marriage ceremonies in honour of this god were originally called as "hymn". As virginity ends with consumption of marriage, "Hymn" was mistakenly associated with chastity. According to Greek mythology, Goddess Hera is the patron of marital relationships and Goddess Aphrodite (also known as Venus) is the supporter of extramarital affairs. The God Hymn has no influence over sexual intercourse of people. Therefore, linking "hymen vaginalis" with virginity appears to be a mythological misinterpretation. Several scientific articles also have proven that hymen may be torn not only during coitus but also because of sports activities, usage of tampon and speculum examinations by gynaecologists $[4,5]$. Contrastingly, a recent study revealed that hymen was intact in as many as $52 \%$ of adolescent girls who admitted to have had sexual intercourse [6]. Hymen is relatively a bloodless membrane and it is unlikely to bleed significantly even if it is torn. Violent penile penetration leading to minor laceration of vaginal wall rather than that of hymen appears to be responsible for "blood stained bed-sheets". Therefore, promoting the concept of intact hymen as a sign of virginity is nothing but perpetuation of myth.

Secondly, is it acceptable to invent and promote a surgical technique which has no valid scientific indication and which simply promotes misbeliefs? Do financial rewards of hymenoplasty dissuade surgeons from educating the public against this misbelief? [7] Although these questions are genuine, the answers to them are not straightforward. When religious circumcision is well accepted by modern surgery, 


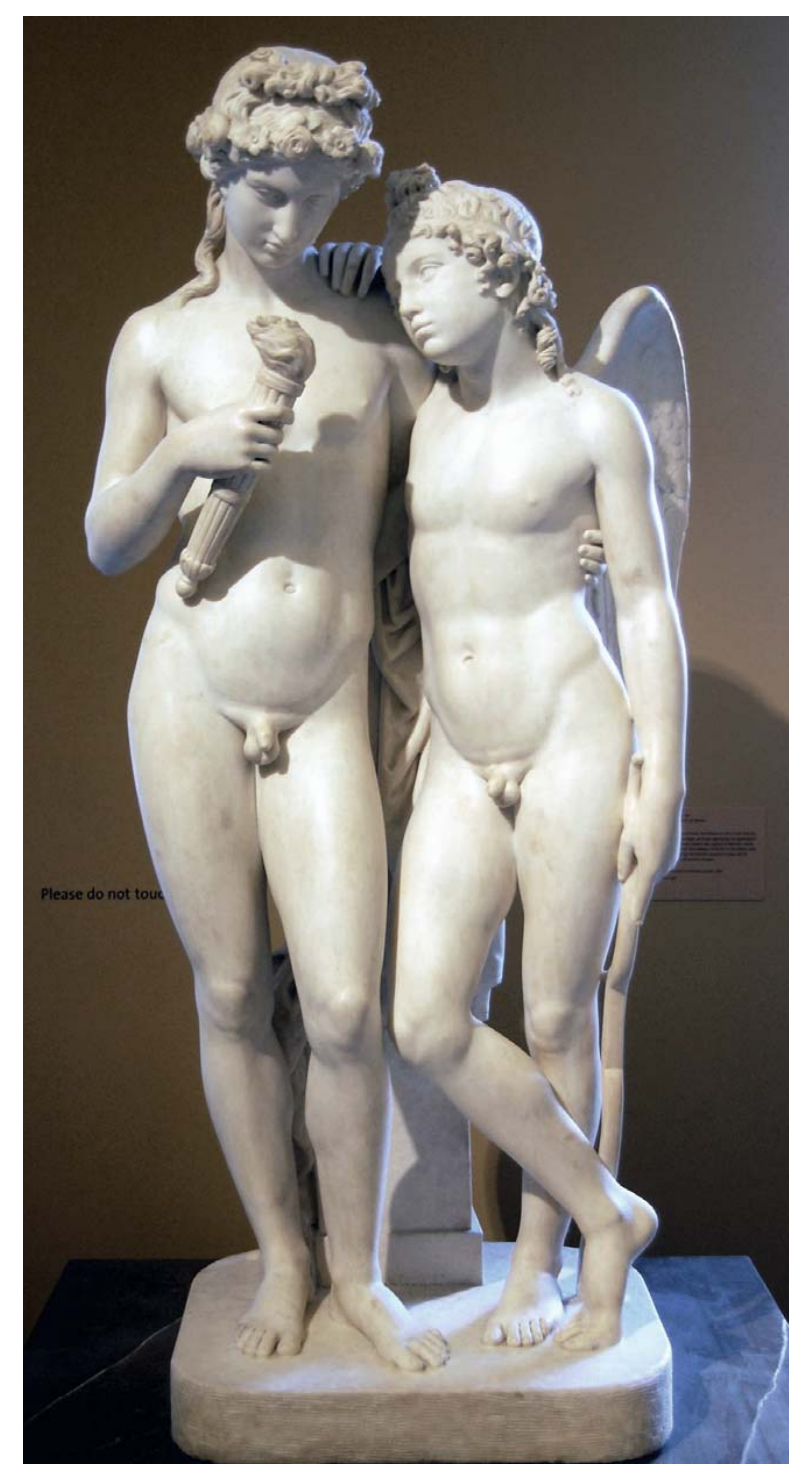

Fig. 1 Ancient marble statue of Hymn (God of marriage - holding a torch) and Eros (god of love) displayed at Victoria - Albert Museum, London

we cannot have a different yard-stick for hymenoplasty. It is the needs of the society that frequently dictates science. If modern surgery would deny the option of hymenoplasty, then the needy women will fall prey to quack surgeons who will do the same job secretly for exorbitant charges [2]. Therefore, in the best interest of needy women scientific surgery, with an open mind, should accept hymenoplasty as an option.

Thirdly, if hymenoplasty is accepted in principles, the reconstructed part is expected to resemble the natural structure. Unfortunately there is no morphological prototype of hymen which can be considered as standard [8,9]. The appearance of hymen is variously described as cribriform, eccentric, septate, annular, crescentic, denticulate, infundibuliform, subseptus, microperforated, vertical and sculptatus [10-12]. It is not clear as to which of these nor- mal variations the plastic surgeon is trying to emulate in his repair. It is complicated by the fact that hymenal morphology changes with advancing age [13-16]. Statistical data on the prevalence of age-related morphological type of hymen is non-existent. This is further complicated by the suggestion that hymenal morphology even varies among various ethnic groups $[17,18]$. Unless standards of normal hymen are established, reconstructive efforts will be not only futile but also deceitful.

Fourthly, what should be the diameter of the hymenal opening that can be considered as intact hymen? Scientific data to answer this crucial question are scarce and the debate is endless $[19,20]$. None of the authors of hymenoplasty have ever addressed this issue. It appears that they arbitrarily narrow the vaginal orifice. Will not such narrowing be a form of genital mutilation? [21] The answer depends upon if the surgical procedure is going to leave behind significant scarring. Scars of vaginal interoitus may cause painful coitus (dyspareunia) and may interfere with vaginal delivery at a later date. Intriguingly, as suggested by preliminary evidences, hymen heals without significant scarring [22]. But there is a need to create unbiased, scientifically robust evidence in support of this preliminary observation.

Fifthly, prospective clients of hymenoplasty do not seem to undergo rigorous psychological testing and preoperative counselling [23]. These prerequisites are essential in other plastic reconstructive works to avoid unrealistic expectations and legal litigations. Such problems are unlikely to arise even with highly unsatisfactory hymenoplasty because these operations are done under high secrecy and because the clients are frequently over-ridden by feelings of guilt. Many times the clients will disappear after surgery and are not available for follow-up evaluation. For the sake of confidentiality medical records are often destroyed at discharge of the client [24]. Hence, objective critical evaluation of results is impractical. Consequently, women undergoing this surgery are more vulnerable for surgical exploitation [2]. Such mistreatments can be minimized only if these surgeries are done at selected regional centres by highly trained surgeons. The results of these accredited centres must be critically, albeit confidentially, audited by a panel of unbiased independent experts. This procedure should not be done by everyone at every centre, lest it will amount to quackery under the disguise of science.

Finally, ethical and social concerns that surround this procedure are abundant. Theoretically a woman may request hymenoplasty with every divorce and re-marriage. Are there any technical and ethical limitations on the number of hymenoplasty that can be done for one individual? [24] Does the surgeon has any vicarious responsibility to the prospective husband or boyfriend who will be deceived by hymenoplasty? Following hymenoplasty if chastity certificate is requested by court of law or by the prospective life-partner, what is expected of the surgeon to do? [25] Lives of surgeons who offer hymenoplasty are not 
infrequently threatened by religious fundamentalists [2]. Is it prudent to perform a surgical operation antagonizing the society? If hymenoplasty is acknowledged as a scientific procedure, will there be a conflict between science and law especially in Muslim countries where hymenoplasty is illegal? Theologists, social activists and legal experts rather than surgeons are the right persons to find answers for these questions.

In conclusion, the principle of hymenoplasty is ethically controversial and the technique is anecdotal. This procedure should be scientifically studied before it is recommended for routine clinical use. Surgeons should have open mind while critically evaluating the usefulness of hymenoplasty. A task force involving surgeons, lawyers, social activists, champions of human-rights and religious leaders is essential to solve the problems surrounding this unusual procedure.

Conflict of interest The author does not have any disclosable interest

\section{References}

1. Hobday AJ, Haury L, Dayton PK (1997) Function of the human hymen. Med Hypotheses 49:171-173

2. Boras SD (2006) Rhetorical limitations and possibilities of technological embodiment and the 'plastic body': A critical analysis of cosmetic body alteration and the hymenoplasty procedure. Master of Arts Thesis; Department of Communication, Miami University, Ohio. Advisor Dr. Ben Voth

3. Houtzager G (2003) The complete encyclopedia of Greek mythology. Rebo Publishers, Netherlands. Entry: Hymen; pp 148-149

4. Rogers DJ, Stark M (1998) The hymen is not necessarily torn after sexual intercourse. BMJ 317:414

5. Goodyear-Smith FA, Laidlaw TM (1998) Can tampon-use cause hymen changes in girls who have not had sexual intercourse? A review of the literature. Forensic Sci Int 94: $147-153$

6. Adams JA, Botash AS, Kellogg N (2004) Differences in hymenal morphology between adolescent girls with and without a history of consensual sexual intercourse. Arch Pediatr Adolesc Med 158:280-285

7. Paterson-Brown S (1998) Should doctors reconstruct the vaginal introitus of adolescent girls to mimic the virginal state? Education about the hymen is needed. BMJ 316:461

8. Curtis E, San Lazaro C (1999) Appearance of the hymen in adolescents is not well documented. BMJ 318:605

9. Edgardh K, Ormstad K (2002) The adolescent hymen. J Reprod Med 47:710-714

10. Mor N, Merlob P, Reisner SH (1986) Types of hymen in the newborn infant. Eur J Obstet Gynecol Reprod Biol 22: 225-228

11. Gardner JJ (1992) Descriptive study of genital variation in healthy, nonabused premenarchal girls. J Pediatr 120:251-257

12. Berenson AB, Heger AH, Hayes JM, Bailey RK, Emans SJ (1992) Appearance of the hymen in prepubertal girls. Pediatrics 89:387-394

13. Berenson A, Heger A, Andrews S (1991) Appearance of the hymen in newborns. Pediatrics 87:458-465

14. Berenson AB (1993) Appearance of the hymen at birth and one year of age: a longitudinal study. Pediatrics 91:820-825

15. Berenson AB (1995) A longitudinal study of hymenal morphology in the first 3 years of life. Pediatrics 95:490-496

16. Berenson AB, Grady JJ (2002) A longitudinal study of hymenal development from 3 to 9 years of age. J Pediatr 140:600-607

17. Al Herbish AS (2001) The hymen morphology in normal newborn Saudi girls. Ann Saudi Med 21:188-189

18. Onderoglu S, Aksit D, Onderoglu LS (1993) The configuration of prepubertal hymen in Turkish population and its clinical aspect. Okajimas Folia Anat Jpn 70:35-39

19. Goodyear-Smith FA, Laidlaw TM (1998) What is an 'intact' hymen? A critique of the literature. Med Sci Law 38:289-300

20. Berenson AB, Chacko MR, Wiemann CM, Mishaw CO, Friedrich WN, Grady JJ (2002) Use of hymenal measurements in the diagnosis of previous penetration. Pediatrics 109: 228-235

21. O'Connor M (2008) Reconstructing the hymen: mutilation or restoration? J Law Med 16:161-175

22. McCann J, Miyamoto S, Boyle C, Rogers K (2007) Healing of hymenal injuries in prepubertal and adolescent girls: a descriptive study. Pediatrics 119:e1094-e1106

23. Goodman MP, Bachmann G, Johnson C, Fourcroy JL, Goldstein A, Goldstein G, Sklar S (2007) Controversies in sexual medicine: is elective vulvar plastic surgery ever warranted, and what screening should be conducted preoperatively? J Sex Med 4:269-276

24. Usta H (2000) Hymenorrhaphy: what happens behind the gynaecologist's closed door? J Med Ethics 26:217-219

25. Amy JJ (2008) Certificates of virginity and reconstruction of the hymen. Eur J Contracept Reprod Health Care 13: $111-113$ 